University of Nebraska - Lincoln

DigitalCommons@University of Nebraska - Lincoln

Faculty Publications in Educational

Administration

Educational Administration, Department of

7-16-2020

Post-Undergraduate Narratives of Queer Men of Color's

Resistance in Culturally Based Fraternities

Antonio Duran

Crystal Garcia

Follow this and additional works at: https://digitalcommons.unl.edu/cehsedadfacpub

Part of the Educational Administration and Supervision Commons

This Article is brought to you for free and open access by the Educational Administration, Department of at DigitalCommons@University of Nebraska - Lincoln. It has been accepted for inclusion in Faculty Publications in Educational Administration by an authorized administrator of DigitalCommons@University of Nebraska - Lincoln. 


\title{
Post-Undergraduate Narratives of Queer Men of Color's Resistance in Culturally Based Fraternities
}

\author{
Antonio Duran \& Crystal Eufemia Garcia \\ Auburn University \\ Correspondence: Antonio Duran, Auburn University, Auburn, AL 36849-5412, USA. \\ Email: antonio.alberto.duran@gmail.com \\ ORCID Antonio Duran http://orcid.org/oooo-0oo2-399o-6796
}

\begin{abstract}
This narrative study examined the involvement of Queer Men of Color in culturally based fraternities beyond their undergraduate years. Eight Queer Men of Color discussed how they saw hypermasculine and heterosexist behaviors occurring in online spaces, local chapters, and on a national level. Findings revealed how participants enacted resistance including challenging problematic behaviors, supporting other queer individuals navigating these spaces, and separating themselves from toxic climates. Implications are offered for future research and practice.
\end{abstract}

Recent years have seen an increase in scholarship about attitudes present in culturally based fraternities related to masculinities and sexuality (Anderson et al., 2011; DeSantis \& Coleman, 2008; Jenkins, 2012; Khoury, 2013; McClure, 2006; McGuire et al., 2018). What these studies reveal are multifaceted pictures of fraternities' openness to

Citation: Antonio Duran \& Crystal Eufemia Garcia (2020): Post-Undergraduate Narratives of Queer Men of Color's Resistance in Culturally Based Fraternities, Journal of Student Affairs Research and Practice, DOI: 10.1080/19496591.2020.1772083

Copyright (C) 2020 NASPA; published by Routledge/Taylor \& Francis. Used by permission. Published 16 July 2020. 
identities and expressions that exist outside of dominant norms, such as queer identities or men who resist hypermasculine ideals. Though some scholars highlighted how members of these organizations can be hostile toward queerness and emphasize hypermasculinity (e.g., DeSantis \& Coleman, 2008; Jenkins, 2012; Williams, 2017), similar issues exist in historically White fraternities. Additionally, the cisheteropatriarchy that manifests in culturally based fraternities is intricately connected to post-Civil Rights era due to ways that these organizations became institutionalized within the academy, leading to an idealized minoritized subject together with a rejection of more critical gendered and sexualized politics (Mahoney, 2019). Other researchers called for more holistic accounts of culturally based fraternities; this would include understanding sociocultural histories that inform the prioritization of hypermasculinity (Anderson et al., 2011) and the positive forms of masculinities that exist in these spaces (McGuire et al., 2018).

Largely missing is research that centers the experiences of marginalized individuals within culturally based fraternities and specifically, Queer Men of Color (QMOC). What does exist typically describes the heterosexist environments present in these organizations that disproportionally affect QMOC (e.g., DeSantis \& Coleman, 20o8; Jenkins, 2012; Khoury, 2013). Due to the limited scholarship, Garcia and Duran (2020) argued that questions remain of how those who identify with multiple marginalized identities experience these fraternal spaces, especially across different settings and stages of involvement. With the awareness that these organizations may perpetuate hegemonic norms surrounding masculinities and sexuality (DeSantis \& Coleman, 2008; Jenkins, 2012; Mahoney, 2019), scholars would benefit from accounts on how QMOC practice resistance within their fraternities.

Using Queer of Color Critique (QOCC; Brockenbrough, 2013; Ferguson, 2004, 2018) as a theoretical framework, this narrative study sought to understand how QMOC reacted to potential cultures of hegemonic masculinity and heterosexism within culturally based fraternities. Because research exists on how individuals experience culturally based fraternities on college campuses (see Garcia \& Duran, 2020), we were particularly interested in participants' continued engagement with fraternities after they graduated from their undergraduate institutions. The research questions guiding this study were as follows: 
1. Where do QMOC encounter oppression relating to sexuality and masculinities within culturally based fraternities after their undergraduate years, if at all?

2. How do QMOC describe practicing resistance in response to manifestations of oppression if it is experienced within their culturally-based fraternities?

Equipped with the knowledge of how QMOC are agentic in face of oppressive structures present in fraternities, student affairs professionals can learn how to support these individuals as they prepare to leave their undergraduate institutions and potentially maintain involvement with their organization. Furthermore, fraternal organizations themselves are better equipped to create equitable spaces for those at the intersections of multiple marginalized identities during and beyond one's undergraduate career. Finally, scholars will benefit from seeing the use of QOCC (Brockenbrough, 2013; Ferguson, 2004, 2018) as a framework that interrogates oppressive systems while centering the resistance that Queer People of Color exercise.

\section{Scholarship on Culturally Based Fraternities: Masculinities and Sexuality}

In response to systemic exclusion from historically White fraternal organizations, culturally based fraternities emerged out of a need to serve Students of Color and other minoritized groups (Torbenson \& Parks, 2009). More current scholarship communicates the beneficial impact of culturally-based organizations on Students of Color (Guardia \& Evans, 2008; McGuire et al., 2018), such as affirming their racial/ethnic identities or providing them with a sense of belonging at their institution. Similar to historically White fraternal organizations, culturally based fraternities have been the subject of investigation concerning masculinities and heteronormativity. Although much of this research focuses on historically Black fraternities within the NPHC, some literature also exists on Latino and Asian American fraternities. We highlight results from these studies here while recognizing that these findings do not insinuate that problematic behaviors around masculinities and heteronormativity exclusively manifest within culturally based organizations nor are they centralized within NPHC fraternities. 
As mentioned previously, researchers have explored issues of masculinities and sexuality within these organizations. First, scholars acknowledged that culturally based fraternities function as sites for productive forms of masculinities, those that resist hypermasculine ideals and that embrace different ways of being "masculine" (e.g., McClure, 2006; McGuire et al., 2018). For example, McClure (2006) communicated how students in a historically Black fraternity believed that the ways they performed masculinities was distinct from cultural images found in media around Black men, which portrayed them as "emotionally hardened and shutoff from their emotions" (p. 62). McGuire et al.'s (2018) research on Black Christian fraternity men showcased how individuals embodied notions of brotherhood by supporting their peers and showcasing more intimate manifestations of masculinities. Likewise, scholarship on Latino fraternities demonstrates ways members enact productive masculinities to lift one another up within the hermandad (brotherhood; Estrada et al., 2017; Garcia, 2019; Guardia \& Evans, 2008).

Although culturally based fraternities can be places where productive forms of masculinities prosper, other research has shown how these organizations can perpetuate hegemonic norms of masculinities and heterosexism (Chen, 2009; DeSantis \& Coleman, 2008; Garcia \& Duran, 2020; Jenkins, 2012; Khoury, 2013; Williams, 2017). The act of acting hypermasculine- typically associated with enduring more violent pledging practices, engaging in hypersexual behaviors, or denouncing femininity-has been well documented. Chen's (2009) work, for instance, discussed ways members of Asian American fraternities rejected racialized stereotypes of Asian American men by embracing hypermasculinity in fraternal activities like hazing practices. However, the attention to hypermasculine ideals typically focus on the collegiate environment or on the new member process without considering how these norms continue beyond a person's time at a higher education institution. On a separate note, the assumptions people have about masculinities oftentimes translates to the attitudes that members hold about sexuality. To this point, Khoury (2013) described, "this [hypermasculine] sense of masculinity is essentially opposed to homosexuality" (p. 148). Other scholars have made the same connections between the investment in certain forms of masculinities and beliefs around sexuality (DeSantis \& Coleman, 2008; Williams, 2017). 
Consequently, QMOC are oftentimes marginalized in culturallybased fraternities. DeSantis and Coleman (2008) underscored this reality in their research on heterosexual men in Black Greek-letter organizations, finding that some individuals were likely not to accept QMOC for fear of how outsiders would perceive their chapter (e.g., "the gay chapter"). This worry was heightened based on how potential members performed femininity. Williams's (2017) research offered another point-of-view to this issue, arguing that the extent to which homophobia occurred varied based on how much individuals aligned with masculine ideals. This research reveals why it is imperative to explore the interconnections of masculinities and sexuality within these contexts, especially beyond the new member process.

\section{Epistemology and Theoretical Framework}

This study used critical theory (Kincheloe \& McLaren, 2011) as its epistemological foundation to illuminate how systems of power and oppression influenced the lives of QMOC in culturally based fraternities. Critical theorists explain how larger sociocultural discourses and structures shape the realities of people's social experiences, privileging certain groups over others. By interrogating unequal distributions of power, critical theory hopes to deconstruct these systems and empower marginalized populations in the process.

As a form of critical theory, we employed Queer of Color Critique (Ferguson, 2004, 2018) as our theoretical framework. QOCC represents both a "convergence and a departure from queer studies" (Ferguson, 2018, para. 2), contesting academic disciplines' tendencies to investigate issues pertaining to sexuality without examining how race and racism disproportionately affect Queer People of Color. QOCC emerged as an attempt to explain and contest the marginalization of Queer People of Color within a larger capitalist society. Combining cultural and economic/materialist analyses, QOCC has emerged in fields such as sociology, cultural studies, and recently, education (Brockenbrough, 2013). Particularly relevant to this study, this critique sheds light on how Queer People of Color practice agency within these structures (Brockenbrough, 2013; Ferguson, 2018). Rather than simply illustrate the systemic issues that Queer People of Color face, this 
framework unearths how individuals enact resistance. Though its use in higher education is limited, examples exist of scholars mobilizing the framework, such as Means and Jaeger (2013) employing QOCC to highlight how Black gay male students experienced homophobia while at the same time embracing their sexuality or Coleman et al. (2020) leveraging QOCC to reimagine Black queer and trans student retention issues due to its focus on structural oppression.

\section{Study Design}

We selected narrative inquiry (Clandinin \& Connelly, 2000; Josselson, 2011) as the methodology suitable to answer the research questions. Narrative inquiry researchers asserted that "people live and/or understand their lives in storied forms, connecting events in the manner of a plot that has a beginning, middle, and end points" (Josselson, 2011, p. 224). Narrative scholars embrace this belief and attempt to understand the ways in which people make sense of their experiences, paying attention to how people discuss events-both thematically and structurally. Narrative inquiry is attentive to three main dimensions of a person's storied realities: the contexts in which they engage, their personal and social interactions, and the temporal nature of their narratives (Clandinin \& Connelly, 2000).

\section{Participant Recruitment and Selection}

To recruit and select participants for this study, we followed Creswell and Poth's (2018) recommendations for criterion sampling. Specifically, individuals were eligible for the study if they fit the following criteria: (a) identified with the umbrella term of queer; (b) identified as a Person of Color; (c) identified as a man aged 18 years or older; and (d) was a member of a culturally based fraternity. We distributed information about the study via social media avenues (i.e., Facebook, Twitter, and Instagram). Interested individuals filled out an initial demographic form. From 13 individuals who expressed interest, we selected 9 based on their adherence to study criteria, as well as their completion of the informed consent process. Though we were open to recruiting additional participants, we focused on these nine 
Table 1. Profile of Queer Men of Color (Self-reported on a Demographic Form)

\begin{tabular}{|c|c|c|c|c|c|}
\hline Name $e^{a}$ & Pronouns & Race/ Ethnicity & $\begin{array}{l}\text { NPHC } \\
\text { or MGC } \\
\text { Organization? }\end{array}$ & $\begin{array}{l}\text { Organization } \\
\text { Name }\end{array}$ & $\begin{array}{l}\text { Years Since } \\
\text { Graduating from } \\
\text { Undergraduate } \\
\text { Institution }\end{array}$ \\
\hline Aaron & $\mathrm{He} / \mathrm{him}$ & African American & NPHC & Upsilon & 10 Years or More \\
\hline August & $\mathrm{He} / \mathrm{him}$ & Black & NPHC & Omicron & 1-3 Years \\
\hline Derek & $\mathrm{He} / \mathrm{him}$ & Latino & MGC & Phi & 1-3 Years \\
\hline Evan & $\mathrm{He} / \mathrm{him}$ & African- American & NPHC & Upsilon & 10 Years or More \\
\hline Jeff & $\mathrm{He} / \mathrm{him}$ & Black & NPHC & Upsilon & 10 Years or More \\
\hline Komplexity & $\mathrm{He} / \mathrm{him}$ & African- American & NPHC & Tau & 7-9 Years \\
\hline Scott & $\mathrm{He} / \mathrm{him}$ & Black & NPHC & Omicron & 10 Years or More \\
\hline Valentino & $\mathrm{He} / \mathrm{him}$ & Afro Latinx & MGC & Phi & 7-9 Years \\
\hline
\end{tabular}

a. Pseudonyms used for research participants and their organizations

participants since they represented diverse experiences in culturally based organizations, which would allow us to critically analyze their individual narratives. Because one participant did not complete all forms of data collection, we made the decision to center the narratives of the remaining eight QMOC in this article. Though limited by the fact that only those who identified as Black or Latino participated, these stories provide important insight into culturally based fraternities broadly. For information about the participants (e.g., social identities and fraternal affiliations), see Table 1.

\section{Data Collection}

These QMOC engaged in two forms of data collection. First, individuals participated in two semi-structured interviews, each lasting approximately 60 to 90 minutes. The interviews focused on the journeys that the QMOC had undergone as it relates to culturally based fraternities. During these interviews, participants shared events and moments that exemplified their experiences, aligning with narrative inquiry's intention to elicit stories (Clandinin \& Connelly, 2000; Josselson, 2011). For the purposes of this project, we examined how individuals described their experiences with fraternities after they graduated. Specifically, the second interview built upon stories participants shared in the first interview, leading us to develop questions such as "In what ways have you seen your organization perpetuate messages 
about queerness after your experiences as an undergraduate student? Tell us a story that exemplifies your answer," as well as "Share a time when you pushed for change in your organization as it relates to sexuality and/or gender." In addition to semi-structured interviews, participants also wrote reflection journals where they were similarly asked to reflect on formative moments within their organizations.

\section{Data Analysis}

In transcribing the first set of interviews and reading the reflection journals, we wrote down preliminary jottings (Saldaña, 2016) of significant themes, which we then used to develop the second interview protocol. After all data were collected, we continued our analysis by engaging in initial coding (Saldaña, 2016). We then followed Polkinghorne's (1995) suggestion to synthesize people's experiences into story/ies. To do so, we constructed narratives for each participant, highlighting their post-undergraduate experiences. We analyzed these narratives by comparing across participants' stories, particularly as it related to narrative inquiry's three-dimensional components (i.e., personal/social, contextual, and temporal; Clandinin \& Connelly, 2000). In these readings and our debriefing conversations, we were attentive to QOCC's focus on Queer of Color marginality and how people exercise agency (Ferguson, 2018). We concluded by employing axial coding (Saldaña, 2016) to refine the relationships among the emerging themes, which led to the findings.

\section{Trustworthiness}

To ensure the rigor of this narrative study, we fulfilled several standards of trustworthiness: credibility, transferability, dependability, and confirmability (see Morrow, 2005). We attended to credibility, described as using others to confirm findings (Morrow, 2005), by engaging in a member-checking process. Following the conclusion of data analysis, we invited participants to provide their feedback on initial themes. Four participants confirmed that the themes represented their experiences while the other individuals did not respond to the request. We also addressed transferability by including rich quotes and descriptions of the participants' narratives to ensure that readers 
could translate findings to their contexts. We adhered to the final two criteria by writing analytical memos since these forms of trustworthiness require that researchers track the inquiry process (dependability), together with making clear connections between findings and the data (confirmability).

\section{Researcher Positionality}

Inherent to narrative inquiry is the belief that stories are co-constructed between the researcher and the participant (Clandinin \& Connelly, 2000; Josselson, 2011). Consequently, it is imperative that narrative scholars make clear their subjectivities to illustrate how they played a role in the research. We further explain our backgrounds in the following statements: Antonio Duran (he/him) identifies as a queer Latino man whose research focuses on how Queer People of Color navigate collegiate environments. Namely, Antonio seeks to understand how people negotiate their identities in siloed marginalized communities (e.g., groups that focus on sexuality or race). Antonio entered into this project not affiliated with a culturally-based frater-

nity and thus asked multiple critical questions interrogating norms of these organizations. Crystal Garcia (she/her) identifies as a multiracial Latina and White, heterosexual cisgender woman. She was not a member of a culturally based sorority, but is a member of a National Panhellenic Sorority. Her experiences serving as a chapter advisor and assisting the fraternity and sorority life (FSL) office with FSL initiatives at her previous institution provided insight to the ways culturally based fraternal organizations are situated within those structures. Because she does not identify as queer or a Man of Color, she reflected on her positionality through journaling and discussions with Antonio about ways she made meaning of participants' narratives.

\section{Findings}

From the perspective of QOCC (Ferguson, 2004, 2018), participants revealed how culturally based fraternities furthered heterosexism and hegemonic masculinity. In response, QMOC enacted forms of resistance, including challenging explicit and implicit problematic 
behaviors, supporting other queer individuals navigating these environments, and separating themselves from toxic climates. To align with narrative inquiry's attention to the settings that people navigate (Clandinin \& Connelly, 2000), we focus our findings on three spaces that QMOC discussed navigating marginality: online, graduate and undergraduate chapters, together with national conventions and involvement.

\section{“If I Don't Say Something, I'm Just as Guilty:" Moving through Online Spaces}

One context where QMOC described negotiating issues about masculinities and sexuality involved online spaces (e.g., social media sites like Facebook). Namely, participants detailed instances in which assumed-heterosexual brothers posted homophobic comments about queer issues or directed toward queer members. For example, August (a member of Omicron) recounted gaining access to National Pan-Hellenic Council (NPHC) Facebook groups after crossing into his organization. He spoke about the response that NPHC members received during Pride month:

There were a lot of attacks on individuals in other NPHC fraternities that attended the Pride Parade in their letters in support ... There were a lot of hateful comments and there was a lot of slurs that were absolutely unnecessary that were directed towards these individuals.

Though August did not initially expect these behaviors coming from a welcoming undergraduate chapter, these experiences provided him a different perspective about how culturally based fraternities treated QMOC. August's stories resembled those of others in the study. In response to these posts, QMOC engaged in individual and collective forms of resistance to this rhetoric. Although not every participant was able to safely engage in this resistance as undergraduates, they were often in a better position to do so after graduation.

Individually, participants responded by exposing the hypocrisy they saw in brothers' comments. For example, Komplexity (a member of Tau) was no stranger to hate on social media. Having crossed in a 
graduate chapter, Komplexity expressed that he was happy to affiliate with his fraternity at this point in his life. This contentment stemmed from the fact that his graduate chapter was accepting of his sexuality. On the other hand, he encountered homophobic statements online. In fact, he recalled an instance when a brother posted, "I can't believe that they're letting this fag into the fraternity and then he did, hashtag my name." Though the post was not publically available (and thus did not allow him to respond), Komplexity remarked that he is a person that would respond to such statements. After this occurrence, he reflected upon a time when he observed comments in a Tau Facebook group equating queerness to sin. Komplexity replied to the post by saying, "So how can you call yourself a Christian, when you are using such a derogatory language towards the LGBTQ community?" This comment invited questions from brothers in other chapters about his own sexuality (e.g., "Are you gay? It takes one to know one.”), but Komplexity kept emphasizing the issue with homophobic language. Making sense of this event, Komplexity mentioned that it was his responsibility as a queer person to do so: "And I feel if I don't say something, then I'm just as guilty."

Aside from individual resistance, participants acknowledged how they would connect with other QMOC to challenge this rhetoric. Evan (a member of Upsilon) spoke about interactions on the Upsilon Facebook Group, which he referred to as perpetuating "lot[s] of heavy misogyny and it's very hyper sexualized." When a brother posted saying that "homosexuality is threatening the masculinity in the Black community," Evan and other brothers who were a part of a same-gender loving Upsilon GroupMe intervened on the Facebook Group and shared the fact that "masculinity is a social construct." Though "their fragile and toxic masculinity was being threatened," Evan found it a worthwhile endeavor to educate them. When asked to discuss his resistance to these norms on social media, Evan felt confident sharing these thoughts in this medium: “... In some cases, I still may not feel comfortable enough to directly, bring it out in front of somebody. But at least from a virtual perspective, I can do it now." While social media was a tool for members to express homophobic perspectives, it was also a platform for members like Evan to challenge those ideas. With the help of others, he felt able to resist matters of homophobia. Similarly, Scott (a member of Omicron) told a story about how assumed 
heterosexual brothers labeled him and other brothers as queer solely based on how they appeared on social media. These individuals then responded by banding together and actively posting against these negative comments: "We would come together on the sidelines and be like, Okay, y'all. So who's going to comment? ... If they want to group us together then we will mobilize together.” Together, these QMOC found support with queer brothers to practice their agency.

\section{“I Offered up My Expertise:" Engaging with Alumni and Undergraduates}

Apart from social media, QMOC mentioned their involvement on the local level with culturally based fraternities (i.e., with alumni chapters or undergraduate chapters) as sites for resistance. Like the virtual space, participants shared how they quickly noted hypermasculine and heterosexist ideals within their local contexts. Whether it was serving in formal contexts (e.g., as advisors), informally supporting undergraduate chapters, or discussing toxic behaviors, these men resisted norms by taking calculated steps to name and educate their fellow brothers about problematic actions.

QMOC who crossed during their undergraduate career mentioned that they had a different approach to confronting heterosexism and hypermasculinity after they graduated. This involved people leaving their undergraduate chapters and then investing their energies in transforming the culture of other undergraduate/alumni chapters. One example of this is seen in the narratives that Jeff shared about his experiences in Upsilon. Specifically, Jeff stated that his time distant from his undergraduate chapter caused him to start asking, "This can be very toxic right? Like this can be very, or this is with the big IS, this is kind of toxic," as it relates to issues of hypermasculinity like in the case of a patriarchal fraternal chant. When engaging with alumni and undergraduate chapters after his undergrad experience, Jeff had a new philosophy: "I call out shit a lot more than what I would have even five years ago" because it was not his "understanding of what the brotherhood should be." He then expanded upon this by noting:

I'm just not going to sit there and let somebody be homophobic or I'm not gonna let somebody sit there and be 
misogynistic ... On the journey I'm in, if that's in my space, then not saying anything is being complicit to that is kind of where I am now.

As an FSL advisor after he matriculated from his undergraduate institution, Jeff was more open to interrupting negative behaviors by naming how undergraduate students planned misogynistic programs (e.g., wet t-shirt contests) or how he encountered members in alumni chapters cheating on their wives. Like Jeff, other participants described their experiences resisting norms in local contexts.

For example, Aaron (a member of Upsilon) spoke about his experiences supporting queer undergraduate students in FSL. After graduating, Aaron worked with an undergraduate chapter but still had concerns about how they would perceive his sexuality: "How will I interact with them? Will they accept me? Will they talk about me behind my back?" However, over time, he curtailed his worries and talked with students about his experiences identifying as a queer man. This was important given the fact that he still noticed his Upsilon brothers being "uncomfortable" in situations when people bring queer partners to events. Notably, Aaron did not discuss his sexuality with every student. Rather, Aaron had one-on-one conversations with students as they approached him. His resistance involved providing students tools to navigate these environments:

Because the students that I work with know that I'm Greek and just want to kind of get an idea ... what my journey was. You know, did folks know? Did they not know? Did you hide it? Did you not hide it? Were you scared about going through a pledge process then?

On a personal level, Aaron's efforts allowed him to assist those who faced similar challenges as queer individuals, especially within culturally based organizations.

In addition to Aaron and Jeff, participants like Derek and Valentino made an effort to give back to undergraduate chapters. Derek (a Phi member) shared his journey through his culturally based fraternity. He recalled how he encountered hypermasculine ideals during his undergraduate career. Of note, Derek was the first gay member that his 
chapter had in a while and his intention was to "fight for more like, somewhat equality for like the future gay brothers so that when future gay brothers come, they don't have to deal with it as much." After graduating from his institution, Derek continued advocating for this form of equality:

[I would] go back and actually go talk to them and ask, like what issues they are having with the fraternity ... What issues they have in the chapter, give them my experience and my advice I had or from my outlook of things.

In discussing why he did so, Derek shared that he believed "there needs to be gay men who want to join for the actual brotherhood part." For him, working with his undergraduate chapter was a form of resistance, stating that it is necessary "to put the work in to help push that change and bring more influence into it because the more influence you have, the more it can change." Similarly, Valentino (a member of Phi) offered his help to undergraduate chapters in the region. Though he was no longer near his undergraduate chapter, Valentino explained the following: "I do offer help up to some of the brothers from this particular school and another state ... I offered up my expertise." Of note, Valentino mentioned that he would "pick and choose the ways in which [he was] engaged in order to manage some of the negativity from the fraternity." This "negativity" consisted of the "masculine things that run the gamut of being homoerotic" that Valentino continued to see as a member. Thus, Valentino assisted his fraternity but only in ways that would preserve his emotional energy.

\section{"I Don't Have the Energy for That:" Navigating National Conven- tions and Involvement}

Finally, participants articulated how they negotiated and resisted matters of heterosexism and hypermasculinity beyond the local level. This involved divesting from national organizations altogether, in addition to creating subbrotherhoods nationally. QMOC often remarked how they would see harmful behaviors reproduced at national conventions and events, leading them to make intentional decisions about how they wanted to involve themselves in the organization. Jeff, for example, 
discussed his experiences attending a national convention after graduating. He recalled attending business meetings where "it becomes an argument, because each Black ... each man is trying to come off as more masculine, strong, intelligent than another man." Moreover, he mentioned that he noticed people espousing homophobia even if they were engaging in queer relationships themselves: “There's men that have families that have wives and go to these conventions and sleep with other men. I see a lot of hypocrisy in that because they're the first ones to talk about why we can't have gay men." In discussing how he practices agency within these spaces, Jeff stated, “I don't have the energy for that. That's just not what I have the energy for at this stage of my life, at this stage of my career." Though leaders had approached him to get involved nationally, including a queer brother who was attempting to make Upsilon more inclusive, Jeff made an intentional decision to decline because of the emotional cost that it would require on his part. Thus, his resistance consisted of not subjecting himself to spaces that would be damaging to him.

Similarly, Evan made a calculated decision to distance himself even though he graduated being all "gung-ho Upsilon." As he got older, he then asked himself, "What the fuck is going on? Like, what are you all doing?" He referenced the following: "You have all these homophobic things to say. You say, how, you know, homosexuality is a danger to the community, but what about the misogyny? You know, what about the behaviors that you all are exhibiting?" In seeing the behaviors that brothers engaged with beyond his undergraduate chapter, Evan made the choice to fragment himself from the national organization for a while: "So I literally had to step away at least from the heterosexual perspective of Upsilon. You know, and Fraternity and Sorority Life as a whole.” Like Jeff, Evan preserved himself and practiced resistance by separating from the hypocritical behaviors engrained within the organization.

Aside from divesting oneself from the organization, participants described creating nationwide subbrotherhoods consisting of queer members. These subbrotherhoods represented a form of reclaiming one's organization by existing among people who did not further hegemonic behaviors in the same ways that these men saw on the national level. As Scott described, attending Omicron national conventions after graduating looked like a "good old boys club in that-that 
the expectation is that you exude this heterosexuality in things like that." Once he noticed this, he gravitated more toward other queer members: "So it's like we created now this community within the overall community while we're at these leadership opportunities." These contexts and relationships meant that he was no longer "exposed anymore to those behaviors and attitudes as [he] did when [he] was originally mixing [himself] purposefully with heterosexual brothers." Similar to Scott, Valentino found other Phi brothers that respected him and his beliefs more: "My evolution of my involvement with the fraternity has really been, I can only surround myself around brothers of my organization who, at least in some way, shape, or form are ideologically similar to me." Though he initially saw Phi as his "everything forever," resistance for Valentino meant creating subbrotherhoods within Phi whether it was virtually or in person.

\section{Discussion}

By centering QMOC, this research represents a significant intervention into the scholarship on culturally based fraternities, showing how QMOC enacted resistance in ways that intervened in organizational cultures and that preserved their own well-being. For example, one unique contribution of this study concerned the fact that it focused on participants' experiences outside of higher education institutions. This is significant considering that literature on culturally based fraternities has frequently analyzed hypermasculinity and heterosexism during the new member process (DeSantis \& Coleman, 2008; Jenkins, 2012; Khoury, 2013; Williams, 2017). Typically, this reproduction of hegemonic norms includes voting down gay men who wish to affiliate, thus barring them from engaging with these spaces. In contrast, this project questioned what happens when people do join culturally based fraternities, and particularly, what occurs after graduation. The participants' stories, collected using narrative inquiry (Clandinin \& Connelly, 2000; Josselson, 2011), showcased how individuals negotiated manifestations of hypermasculinity and heterosexism beyond their intention to join. This study underscored three contexts where QMOC encountered marginalization.

In addition to simply shedding light on post-undergraduate experiences of QMOC in culturally based fraternities, this study showcases 
how individuals practice resistance to the hypermasculine and heterosexist norms that exist in these organizations (DeSantis \& Coleman, 2008; Jenkins, 2012; Williams, 2017). Although scholarship like Williams's (2017) research on Black gay men in Black Greek-Letter Organizations began centering the voices of QMOC, the participants in this project shared examples of how people engage in agentic behaviors within these spaces. Informed by QOCC (Ferguson, 2004, 2018), we sought to comprehend not only how these members encounter Queer of Color marginality but also to investigate the ways they transform these environments. This took the form of interrupting negative social media behavior (as in the cases of Komplexity, Evan, and Scott's stories), working with undergraduates and undergraduate/alumni chapters (represented in the narratives of Aaron, Derek, Jeff, and Valentino), or creating subbrotherhoods (as seen in Scott and Valentino's examples). What these differing contexts revealed is that QMOC took calculated steps to effect change within their own spheres of influence. Consequently, readers are not left with the impression that QMOC are victims who are subject to hegemonic norms of masculinities and heteronormativity within these organizations. Instead, these individuals have the capacity to contest these ideas that may exist within culturally-based fraternities.

Finally, this study contributes to nuanced notions of resistance within these organizations. Participants like Jeff and Evan both mentioned that their manners of enacting agency consisted of separating themselves in some ways from their fraternity after graduating. From the perspective of QOCC, an analytic framework that examines Queer of Color marginality from a cultural and materialist lens (Ferguson, 2004, 2018), this pattern brings into question the ways in which QMOC negotiate issues of property and capital within organizations. Though Jeff, for example, witnessed another QMOC attempt to reshape the system within Upsilon fraternity, he determined that the energy it would take to do so would not be worth the benefit. In this example, Jeff made an active decision to not incur the psychological and emotional cost of intervening in the dominant discourses he saw in the national organization. Jeff's and Evan's stories represent how organizations may take advantage of the labor of QMOC while also devaluing their identities. These insights are hence crucial to envisioning the different steps that culturally based fraternities can take to generate environments welcoming to QMOC while acknowledging their labor. 


\section{Implications}

Apart from contributing to the literature, the study findings can inform future research and practice as it relates to fraternity and sorority life broadly, but also culturally based fraternities specifically. First, studies would benefit from examining the experiences of queer members who identify as Native or Asian/Asian American in culturally based fraternities. Though we recruited participants in this study seeking QMOC, no Native American or Asian/Asian American individuals submitted interest in the research. We acknowledge that this is a limitation on our part, and we encourage future researchers to further target these groups and/or create separate studies that focus on their experiences in these organizations. Because limited research exists on both of these groups within the culturally based fraternity literature (Torbenson \& Parks, 2009), this represents a potential fruitful area of scholarship. Similarly, a shortage of research interrogates the ways that Queer Women of Color and/or Trans People of Color navigate these organizations, representing another direction for this body of work.

In addition to recommendations for research, this study has numerous implications for practice pertaining to FSL organizations. Though we direct these implications to culturally based fraternities specifically, we find it important to acknowledge that the recommendations that follow would be fruitful for all fraternities and sororities to consider since the issues that participants detailed (e.g., instances of hegemonic masculinity or homophobia) exist in historically White FSL organizations as well. Stories such as Jeff's revealed that participants experienced a significant shift in their willingness to acknowledge and interrupt problematic behaviors in their undergraduate chapters versus those occurring after. What this underscores is that undergraduate institutions of higher education can be doing a better job of creating conditions for those who identify as queer within culturally-based organizations. Thus, those who work on college campuses would benefit from conducting assessments about the experiences of these individuals about the climate of culturally based fraternities. These kinds of assessments could then be integral to creating programs and initiatives that expose all members of fraternity and sorority life to matters of sexuality and heterosexism. Similarly, collegiate environments 
could institute trainings and workshops for culturally based fraternity members to deconstruct ideas of hypermasculinity within these spaces. Providing opportunities for members to consider productive masculinities while in college may influence their enactment of such behaviors beyond their collegiate experience. Finally, institutional FSL offices could also prepare QMOC for the type of interactions that they may encounter after graduating. In doing so, FSL practitioners could serve an integral role in helping individuals to develop the necessary skills for them to navigate fraternal contexts after graduation.

Beyond having implications for undergraduate institutions, the findings highlight that there is a significant need for culturally based fraternities themselves to drastically revisit their practices concerning sexuality. Though organizations may make it a point to state in nondiscrimination policies that they do not actively oppress sexual minorities, stories from the participants suggest that QMOC still encounter marginalizing environments due to societal norms about sexuality. Culturally based fraternities could respond to this by taking active stances when instances of homophobia and heterosexism occur (especially on social media), in addition to offering educational experiences for people to learn about sexuality within an organizational context. This could take the form of having new member educators explicitly state that they support applicants of all sexualities and changing rituals to reflect this belief. At regional and national conventions, organizations could make a concerted effort to include sessions that speak to the sexual diversity within the fraternity and how to support brothers who identify along the sexual spectrum. These moves could shift the cultural around sexuality within these organizations, serving as critical interventions for QMOC.

\section{Conclusion}

In order to add to increasingly complex narratives of culturally based fraternities, this study centered a population that is typically erased within these organizations: Queer Men of Color. From a Queer of Color Critique (Ferguson, 2004, 2018) lens, participants' narratives revealed the enduring legacies of hypermasculinity and heterosexism within these spaces. Additionally, this framework highlighted the agency that 
Queer Men of Color exercised in these organizations whether it was actively naming problematic behaviors, acting as educators within their local contexts, or separating themselves to recuperate and recharge. Highlighting the resistance that these QMOC's stories revealed, Evan stated:

[I have the] potential to change the conversation and change the dynamic ... I have the opportunity to have a seat at tables that some people either may not be able to have or if they are sitting there they don't know what type of conversations to have or how to navigate those conversations.

These words underscore the potential that QMOC have to shape culturally based fraternities for the better, fighting for interconnected issues of justice. However, culturally based organizations must similarly consider the emotional cost of doing this work, actively working toward environments that improve cultures tied to masculinities and sexuality.

\section{References}

Anderson, R., Buckley, P. M., \& Tindall, N. T. J. (2011). Black Greek-letter fraternities and masculinities. In M. W. Hughes \& G. S. Parks (Eds.), Black Greek-letter organizations 2.0: New directions in the study of African American fraternities and sororities (pp. 114-132). University Press of Mississippi.

Brockenbrough, E. (2013). Introduction to the special issue: Queers of Color and anti-oppressive knowledge production. Curriculum Inquiry, 43(4), 426-440. https://doi.org/10.1111/curi.12023

Chen, E. W. (2009). Asian Americans in sororities and fraternities: In search of a home and place. In C. L. Torbenson \& G. Parks (Eds.), Brothers and sisters: Diversity in college fraternities and sororities (pp. 83-103). Rosemont Publishing.

Clandinin, D. J., \& Connelly, F. M. (2000). Narrative inquiry: Experience and story in qualitative research. Jossey-Bass.

Coleman, R. D., Wallace, J. K., \& Means, D. R. (2020). Questioning a single narrative: Multiple identities shaping Black queer and transgender student retention. Journal of College Student Retention: Research, Theory, and Practice, 21(4), 455-475. https://doi.org/10.1177/1521025119895516

Creswell, J. W., \& Poth, C. N. (2018). Qualitative inquiry \& research design: Choosing among five approaches (4th ed.). Sage. 
DeSantis, A. D., \& Coleman, M. (2008). Not on my line: Attitudes about homosexuality in Black fraternities. In G. Parks (Ed.), Black Greek-letter organizations in the twenty-first century (pp. 291-312). The University Press of Kentucky.

Estrada, F., Mejia, A., \& Hufana, A. M. (2017). Brotherhood and college Latinos: A phenomenological study. Journal of Hispanic Higher Education, 16(4), 314-337. https://doi.org/10.1177/1538192716656451

Ferguson, R. A. (2004). Aberrations in Black: Toward a Queer of color critique. University of Minnesota Press.

Ferguson, R. A. (2018, March 28). Queer of color critique. Oxford Research Encyclopedia of Literature. Oxford University Press. http://oxfordre. com/literature/view/10.1093/acrefore/9780190201098.001.0001/ acrefore-9780190201098-e-33

Garcia, C. E. (2019). Belonging in a predominantly white institution: The role of membership in Latina/o sororities and fraternities. Journal of Diversity in Higher Education. Advance online publication. https://doi.org/10.1037/ dheooo0126

Garcia, C. E., \& Duran, A. (2020). "In my letters, but I was still by myself”: Highlighting the experiences of Queer Men of Color in culturally based fraternities. Journal of Diversity in Higher Education. Advance online publication. https://doi.org/10.1037/dheoooo167

Guardia, J. R., \& Evans, N. J. (2008). Factors influencing the ethnic identity development of Latino fraternity members at a Hispanic serving institution. Journal of College Student Development, 49(3), 163-181. https://doi. org/10.1353/csd.0.0011

Jenkins, R. D. (2012). Black fraternal organizations: Understanding the development of hegemonic masculinity and sexuality. Journal of African American Studies, 16(2), 226-235. https://doi.org/10.1007/s12111-010-9149-7

Josselson, R. E. (2011). Narrative research: Constructing, deconstructing, and reconstructing story. In F. J. Wertz, K. Charmax, \& L. M. McMullen (Eds.), Five ways of doing qualitative analysis: Phenomenological psychology, grounded theory, discourse analysis, narrative research, and intuitive inquiry (pp. 224242). Guilford Press.

Khoury, I. (2013). "It's a manhood thing": Pledging, masculinity, and identity development in Black Greek fraternities. In M. C. Brown II, T. E. Dancy II, \& J. E. Davis (Eds.), Educating African American males: Contexts for consideration, possibilities for practice (pp. 139-156). Peter Lang.

Kincheloe, J. L., \& McLaren, P. (2011). Rethinking critical theory and qualitative research. In k. hayes, S. R. Steinberg, \& K. Tobin (Eds.), Key works in critical pedagogy (pp. 285-326). Sense Publishers.

Mahoney, A. D. (2019). Queering Black Greek-lettered fraternities, masculinity and manhood: A queer of color critique of institutionality in higher education [Doctoral dissertation]. University of Louisville Electronic Theses and Dissertation. (Paper 3286). 
McClure, S. M. (2006). Improvising masculinity: African American fraternity membership in the construction of a Black masculinity. Journal of African American Studies, 10(1), 57-73. https://doi.org/10.1007/s12111-006-1013-4

McGuire, K. M., McTier, T. S., Jr., Ikegwuonu, E., Sweet, J. D., \& Bryant-Scott, K. (2018). "Men doing life together": Black Christian fraternity men's embodiments of brotherhood. Men and Masculinities. Advance online publication. https://doi.org/10.1177/1097184X18782735

Means, D. R., \& Jaeger, A. J. (2013). Black in the rainbow: "Quaring” the black gay male student experience at historically Black universities. Journal of African American Males in Education, 4(2), 124-140. http:// journalofafricanamericanmales.com/wp-content/uploads/2013/11/MeansJaeger-2013-1.pdf

Morrow, S. L. (2005). Quality and trustworthiness in qualitative research in counseling psychology. Journal of Counseling Psychology, 52(2), 250-260. https://doi.org/10.1037/0022-0167.52.2.250

Polkinghorne, D. E. (1995). Narrative configuration in qualitative analysis. International Journal of Qualitative Studies in Education, 8(1), 5-23. https:// doi.org/10.1080/0951839950080103

Saldaña, J. (2016). The coding manual for qualitative researchers (3rd ed.). Sage.

Torbenson, C. L., \& Parks, G. S. (Eds.). (2009). Brothers and sisters: Diversity in college fraternities and sororities. Rosemont Publishing.

Williams, J. M. (2017). Ostracized insiders: Exploring the experiences of Black gay men in historically Black Greek letter fraternities [Doctoral dissertation]. https://oaktrust.library.tamu.edu/ 